\title{
Iranian lifestyle factors affecting reflux disease among healthy people in Qom
}

\author{
Ghasem Yadegarfar ${ }^{1}$, Somayeh Momenyan ${ }^{2}$, Mitra Khoobi ${ }^{3}$, Soriyeh Salimi ${ }^{4}$, Amin Sheikhhaeri ${ }^{5}$, Mohsen
} Farahabadi $^{6}$, Saeideh Heidari ${ }^{7}$

${ }^{1}$ Associate Professor, Epidemiology \& Biostatistics Department, School of Public Health, Isfahan University of Medical Sciences, Isfahan, Iran

${ }^{2} \mathrm{PhD}$ Candidate in Biostatistics, Paramedical Sciences Faculty, Shahid Beheshti University of Medical Sciences, Tehran, Iran

${ }^{3} \mathrm{PhD}$ Candidate in Nursing Education, Nursing and Midwifery School, Tehran University of Medical Sciences, Tehran, Iran

${ }^{4}$ Nursing Student, Qom Azad University, Qom, Iran

${ }^{5}$ Nursing Student, Student Research Committee, Qom University of Medical Sciences

${ }^{6}$ Operating Room Student, Student Research Committee, Qom University of Medical Sciences

${ }^{7}$ M.Sc. in Nursing, Faculty Member, Nursing and Midwifery School, Qom University of Medical Sciences. Qom, Iran

\section{Type of article: Original}

\begin{abstract}
Background and aim: Gastroesophageal reflux disease (GERD) is one of the most common digestive system disorders. Life style factors may increase the risk of reflux disease. We aimed to determine prevalence of reflux and related life style-factors in the population living in Qom.

Methods: This cross-sectional study was conducted among 1500 residents of Qom in 2014. Individuals were selected through multi-stage sampling. They completed two questionnaires: FSSG questionnaire for diagnosis of GERD and a general questionnaire to measure demographic and lifestyle factors. Univariate and multivariate were used for analysis of data. Data were analyzed using IBM SPSS version 20.

Results: A total of 1130 individuals were analyzed in which 52.4\% of them were female. Prevalence of GERD was $28 \%$.Adjusted findings showed use of PPIs (OR: 2.2, 95\% CI: 2-5), taking H2RAs (OR: 4.7, 95\% CI: 2.3 9.4), the habit of quick eating (OR: $1.5,95 \%$ CI: 1.1-2), extra salt consumption on daily meals (OR: $1.5,95 \%$ CI: 1.05-2), lack of sleep (OR: 2.6, 95\% CI: 1.5-4.8), and consumption of white bread (OR: 1.7, 95\% CI: 1.05-2.7) were related to increased risk of GERD.

Conclusion: Our findings showed lifestyle factors such as habit of quick eating, extra salt on regular meals, lack of sleep and use of white bread were associate with increased risk of GERD. However, habit of midnight snack, having dinner just before bedtime, lack of breakfast, smoking, drinking tea and coffee were not associated with increased risk of GERD. It is recommended to carry out a cohort study among the Iranian population to evaluate the effect of life-style risk factors on GERD.

Keywords: Gastroesophageal reflux disease, Frequency scale, Life-style factors, Risk factor
\end{abstract}

\section{Introduction}

Gastroesophageal reflux disease (GERD) is a public health problem which defines when the reflux of gastric contents causes troublesome symptoms of heartburn or regurgitation. GERD symptoms represent one of the most frequent health problems in the Western world (1). Trend in the prevalence of GERD is increasing worldwide, but seems to be higher in the West than in the East $(2,3)$. Population-based studies have shown that the prevalence of GERD is higher in Central (7.6-19.4\%) and West Asia (12.5-27.6\%) $(1,4)$. In Iran, the study which was carried out in Tabriz, North-west of Iran, estimated that the prevalence of GERD is $2.7 \%$ (5). Another population-based study in

\section{Corresponding author:}

Somayeh Momenyan. Paramedical Sciences Faculty, Shahid Beheshti University of Medical Sciences, Tehran, Iran. Tel: +98.2537836145, Email: somy.momenyan@gmail.com

Received: January 25, 2017, Accepted: December 12, 2017, Published: April 2018

iThenticate screening: September 21, 2017, English editing: February 14, 2018, Quality control: February 15, 2018

This article has been reviewed / commented by three experts

(C) 2018 The Authors. This is an open access article under the terms of the Creative Commons Attribution-NonCommercialNoDerivs License, which permits use and distribution in any medium, provided the original work is properly cited, the use is non-commercial and no modifications or adaptations are made. 
the capital city of Tehran, reported a prevalence of $18.2 \%$ (6). Also, in Isfahan, the prevalence of GERD, defined as the presence of heartburn sometimes, was often or always reported as $23.5 \%$ in the study population of 4,763 adults (7). Despite the high prevalence of GERD symptoms, however, its etiology is still not completely understood. There are hypotheses that the genetic factor, the Helicobacter pylori prevalence and the change in life-style, dietary factors might have an influence. However, recommended modification in lifestyle and dietary factor is under debate (1). Regarding nutrition, a number of patients and physicians associate the occurrence of reflux symptoms with various dietary factors. As a consequence, patients are often advised to avoid fatty meals, candy, coffee, or tea. However, tests remain inconclusive on the effects of these dietary components on heartburn or regurgitation. There is also controversy regarding the role of alcohol and smoking in causing reflux symptoms (8). Several studies have shown an increased risk of GERD symptoms to be associated with obesity, consumption, dinner just before bedtime, a high dietary fat intake, smoking, intake of non-steroidal anti-inflammatory drugs and sleeping position. Furthermore, several studies provided evidence that gender, age, marital status, socioeconomic status, level of education, family history, and asthma as potential risk factors of GERD (9). Few studies have addressed these issues and the available results are partly conflicting; thus, more research is required until any preventive and accelerator effect of lifestyle on GERD can be better established. In this large population-based survey, we aimed to assess the prevalence of GERD in Qom city (a multicultural city) in Iran (a country which has experienced main dietary changes over the past decades), and to determine the impact of socieconomic and lifestyle factors on GERD symptoms.

\section{Material and Methods}

This cross-sectional study was carried out on 1,500 residents of Qom in 2014. Individuals were selected through multi-stage sampling - the city was divided into 8 strata, then each stratum was classified into clusters. Finally, several clusters were selected randomly, at each stratum. Each individual over 18 years old, without gastrectomy was included in the study. All incomplete questionnaires on life-style and FSSG were excluded. Therefore, 1,130 individuals' data were analyzed. A self-administered questionnaire was used to collect the data. The questionnaire had two parts: the first part included background characteristics such as age, gender, BMI, education level, income level, history of taking digestive medicine, Proton pump inhibitors (PPIs), histamine-2-receptor antagonists (H2Ras), life-style factors including main meal, snacks, late meal, breakfast behavior, vegetable and fruit consumption, oven-cooked meals, taking white bread, red meats, salty meals, tea/coffee consumption, alcohol, carbonated drinks, and regular physical activities. The second part of the questionnaire was "Frequency Scale for the Symptoms of GERD (FSSG)" to evaluate reflux symptoms. It consists of 12 questions to which patients who most often answered "yes" were selected and were assigned scores (never $=0$; occasionally $=1$; sometimes $=2$; often $=3$; and always $=4$ ) to produce a frequency scale for symptoms of GERD (FSSG). The validity of FSSG in comparison with QUEST is acceptable $(10,11)$. To be diagnosed as GERD, the cutoff point of FSSG has been determined as greater than 10 (12). The FSSG scale was translated to a Farsi version by forward-backward method. Then, its content validity was assessed and confirmed by CVI and CVR. The internal consistency was assessed by Cronbach's alpha coefficient which was calculated as 0.85 . Also, the reliability of FSSG was assessed by test retest method, and Pearson correlation was calculated as 0.89 . The dependent variable was binary variable and is divided into having GERD or not. Data were analyzed using multiple logistic regression after applying a univariate model to each background characteristic or risk factor. Crude and adjusted Odds ratios were reported at $5 \%$ significance level accompanied with $95 \%$ confidence intervals. IBM@ SPSSC Statistics version 20 (IBMC Corp., Armonk, NY, USA) was employed for the analysis. The study was approved by the Ethics Committee of Qom University of Medical Sciences. The study protocol was also approved by the Ethics Committee of Qom University of Medical Sciences. An informed written consent was obtained from the patients. Also, no conflict of interest has been declared by the authors. Proposal code was MUQ.REC.1393.135.

\section{Results}

The study was done on 1,130 individuals of whom $48 \%$ were male. Mean age of all participants was $39.4 \pm 10.0$. FSSG mean score was $10.5 \pm 7.7$. Based on this score, prevalence of GERD was estimated as $28 \%$. Table 1 shows the univariate analysis results. The prevalence of GERD was not different between males and females; obese individuals had higher prevalence of GERD than normal weight (71.1 vs. 62\%); participants who took digestive medicine such as H2Ras and PPIs were more at risk of getting GERD $(\mathrm{OR}=8.2, \mathrm{p}<0.001)$ and $(\mathrm{OR}=5.7, \mathrm{p}<0.001)$ respectively; and individual with lower level of education had less risk of GERD than higher education $(\mathrm{OR}=0.7, \mathrm{p}=0.03)$. Table 2 contains the univariate analysis results of life style risk factors. Among all, 11 risk factors appeared to increase risk of GERD significantly: insufficient sleep $(\mathrm{OR}=3.8, \mathrm{p}<0.001)$, drinking carbonated drinks $(\mathrm{OR}=3, \mathrm{p}<0.001)$, having meals very fast $(\mathrm{OR}=2, \mathrm{p}<0.001)$, having salty meals $(\mathrm{OR}=2, \mathrm{p}<0.001)$, having snacks after main meal at night $(\mathrm{OR}=1.8, \mathrm{p}=0.001)$, cigarette smoking $(\mathrm{OR}=1.8, \mathrm{p}=0.02)$, lack of breakfast $(\mathrm{OR}=1.6, \mathrm{p}<0.001)$, lack of regular 
physical activities $(\mathrm{OR}=1.6, \mathrm{p}=0.01)$, drinking tea $(\mathrm{OR}=1.6, \mathrm{p}=0.02)$, having white bread $(\mathrm{OR}=1.6, \mathrm{p}=0.02)$, and eating dinner late $(\mathrm{OR}=1.4, \mathrm{p}=0.002)$. There was no statistically significant relationship between drinking coffee, consuming vegetables and fruits, red meat and fried meals with risk of GERD. Finally, all significant risk factors were entered into the multiple logistic regression model (Table 3). Adjusted results showed taking H2Ras (OR=4.7, $\mathrm{p}<0.001)$, insufficient sleep $(\mathrm{OR}=2.6, \mathrm{p}=0.001)$, taking PPIs $(\mathrm{OR}=2.2, \mathrm{p}=0.045)$, consuming white bread $(\mathrm{OR}=1.7$, $\mathrm{p}=0.02)$, eating meals very fast $(\mathrm{OR}=1.5, \mathrm{p}=0.008)$, having salty meals $(\mathrm{OR}=1.5, \mathrm{p}=0.02)$, and education level $(\mathrm{OR}=0.5, \mathrm{p}=0.004)$ were statistically significant risk factors for GERD.

Table 1. Association of demographic, socioeconomic, and state of drug use with GERD (Univariate analysis)

\begin{tabular}{|c|c|c|c|c|c|}
\hline \multirow{2}{*}{\multicolumn{2}{|c|}{ Factors }} & \multicolumn{2}{|l|}{ Number } & \multicolumn{2}{|l|}{ Univariate } \\
\hline & & No GERD & GERD & OR $(95 \% \mathrm{CI})$ & p-value \\
\hline \multirow[t]{2}{*}{ Gender } & Female & $193(33.6)$ & $382(66.4)$ & $1.1(0.8-1.4)$ & 0.4 \\
\hline & Male & $187(35.8)$ & $335(64.2)$ & (reference) & (reference) \\
\hline \multirow[t]{3}{*}{ BMI status } & Obese & $50(28.9)$ & $123(71.1)$ & $1.5(1.04-2.1)$ & 0.03 \\
\hline & Overweight & $125(33)$ & $245(67)$ & $1.2(0.9-1.6)$ & 0.1 \\
\hline & Normal & $214(38)$ & $349(62)$ & (reference) & (reference) \\
\hline \multicolumn{2}{|l|}{ Age } & $39.9 \pm 10.7$ & $39.1 \pm 9.6$ & $0.99(0.98-1)$ & 0.2 \\
\hline \multirow[t]{3}{*}{ Education level } & $<$ High school & $111(42.4)$ & $151(57.6)$ & $0.7(0.5-0.9)$ & 0.03 \\
\hline & High school & $121(30.6)$ & $274(69.4)$ & $1.1(0.8-1.5)$ & 0.3 \\
\hline & University & $158(34.1)$ & $306(65.9)$ & (reference) & (reference) \\
\hline \multirow[t]{3}{*}{ Income level } & Low & $52(35.6)$ & $94(64.4)$ & $1.2(0.8-2.1)$ & 0.2 \\
\hline & Middle & $281(33.6)$ & $556(66.4)$ & $1.4(1.1-2.06)$ & 0.044 \\
\hline & High & $56(41.8)$ & $78(58.2)$ & (reference) & (reference) \\
\hline \multirow[t]{2}{*}{ Use of PPIs } & Yes & $10(9.4)$ & $96(90.6)$ & $5.7(2.9-11.1)$ & $<0.001$ \\
\hline & No & $384(37.5)$ & $640(62.5)$ & (reference) & (reference) \\
\hline \multirow[t]{2}{*}{ Use of $\mathrm{H}_{2} \mathrm{Ras}$} & Yes & $12(7.3)$ & $152(92.7)$ & $8.2(4.5-15)$ & $<0.001$ \\
\hline & No & $382(39.5)$ & $584(60.5)$ & (reference) & (reference) \\
\hline \multirow[t]{2}{*}{ Use of NSAIDs } & Yes & $107(23.2)$ & $354(76.8)$ & $2.5(1.9-3.2)$ & $<0.001$ \\
\hline & No & $286(43.3)$ & $374(56.7)$ & (reference) & (reference) \\
\hline \multirow[t]{2}{*}{ Use of other digestive drugs } & Yes & $7(12.7)$ & $48(87.3)$ & $3.8(1.7-8.5)$ & 0.001 \\
\hline & No & $385(36.2)$ & $678(63.8)$ & (reference) & (reference) \\
\hline \multirow[t]{2}{*}{ Use of steroids } & Yes & $9(20)$ & $36(80)$ & $2.1(1.04-4.6)$ & 0.03 \\
\hline & No & $383(35.4)$ & $698(64.6)$ & (reference) & (reference) \\
\hline \multirow[t]{2}{*}{ Use of antihypertensive } & Yes & $14(29.8)$ & $33(70.2)$ & $1.2(0.6-2.4)$ & 0.4 \\
\hline & No & $379(35.2)$ & $699(64.8)$ & (reference) & (reference) \\
\hline \multirow[t]{2}{*}{ Use of antihyperglycemic } & Yes & $7(28)$ & $18(72)$ & $1.3(0.5-3.3)$ & 0.4 \\
\hline & No & $386(35)$ & $716(65)$ & (reference) & (reference) \\
\hline \multirow[t]{2}{*}{ History of cardiovascular disease } & Yes & $9(23.7)$ & $29(76.3)$ & $1.7(0.8-3.7)$ & 0.1 \\
\hline & No & $384(35.3)$ & $703(64.7)$ & (reference) & (reference) \\
\hline \multirow[t]{2}{*}{ History of renal failure } & Yes & $21(27.6)$ & $55(72.4)$ & $1.4(0.8-2.4)$ & 0.1 \\
\hline & No & $370(35.5)$ & $673(64.5)$ & (reference) & (reference) \\
\hline
\end{tabular}

Numbers and row percentages (in parentheses). Discrepancies in the totals are due to missing covariate values.

Table 2. Association of life style factor with GERD (Univariate analysis)

\begin{tabular}{|c|c|c|c|c|c|}
\hline \multirow{2}{*}{\multicolumn{2}{|c|}{ Factors }} & \multicolumn{2}{|l|}{ Number } & \multicolumn{2}{|l|}{ Univariate } \\
\hline & & No GERD & GERD & OR $(95 \% \mathrm{CI})$ & P-value \\
\hline \multirow[t]{2}{*}{ Habit of midnight snack } & Yes & $38(23.9)$ & $121(76.1)$ & $1.8(1.2-2.7)$ & 0.001 \\
\hline & No & $355(37.1)$ & $603(62.9)$ & (reference) & (reference) \\
\hline \multirow[t]{2}{*}{ Habit of quick eating } & Yes & $131(26.3)$ & $367(73.7)$ & $2(1.5-2.6)$ & $<0.001$ \\
\hline & No & $261(41.9)$ & $362(58.1)$ & (reference) & (reference) \\
\hline \multirow[t]{2}{*}{ Dinner just before bedtime } & Yes & $172(30.6)$ & $391(69.4)$ & $1.4(1.1-1.8)$ & 0.002 \\
\hline & No & $220(39.2)$ & $341(60.8)$ & (reference) & (reference) \\
\hline \multirow{2}{*}{ Frequent lack of breakfast } & Yes & $107(27.5)$ & $282(72.5)$ & $1.6(1.2-2.1)$ & $<0.001$ \\
\hline & No & $284(38.6)$ & $452(61.4)$ & (reference) & (reference) \\
\hline \multirow[t]{2}{*}{ Habit of alcohol drinking } & Yes & $23(27.7)$ & $60(72.3)$ & $1.4(0.8-2.3)$ & 0.1 \\
\hline & No & $370(35.5)$ & $672(64.5)$ & (reference) & (reference) \\
\hline \multirow[t]{3}{*}{ Habit of smoking } & Current smoker & $19(23.8)$ & $61(76.2)$ & $1.8(1.07-3.1)$ & 0.02 \\
\hline & Former smoker & $19(26.4)$ & $53(73.6)$ & $1.5(0.9-2.7)$ & 0.09 \\
\hline & Never smoker & $349(36.3)$ & $613(63.7)$ & (reference) & (reference) \\
\hline Tea use (Cups per day) & $>3$ & $98(30.9)$ & $219(69.1)$ & $1.6(1.06-2.4)$ & 0.02 \\
\hline
\end{tabular}




\begin{tabular}{|c|c|c|c|c|c|}
\hline & $1-3$ & $230(35.7)$ & $415(64.3)$ & $1.2(0.8-1.8)$ & 0.1 \\
\hline & None & $60(41.7)$ & $84(58.3)$ & (reference) & (reference) \\
\hline \multirow[t]{3}{*}{ Coffee use (Cups per day) } & $>3$ & $4(44.4)$ & $5(55.6)$ & $0.6(0.1-2.4)$ & 0.5 \\
\hline & $1-3$ & $46(38)$ & $75(62)$ & $0.8(0.5-1.2)$ & 0.4 \\
\hline & None & $333(34.5)$ & $632(65.5)$ & (reference) & (reference) \\
\hline \multirow[t]{3}{*}{ Extra salt on regular meals } & Always & $33(26.6)$ & $91(73.4)$ & $2(1.3-3.1)$ & 0.001 \\
\hline & Sometimes & $159(30.5)$ & $363(69.5)$ & $1.6(1.2-2.1)$ & $<0.001$ \\
\hline & Never & $200(42.5)$ & $271(57.5)$ & (reference) & (reference) \\
\hline \multirow[t]{3}{*}{ Fizzy drink } & Always & $20(21.3)$ & $74(78.7)$ & $3(1.6-5.4)$ & $<0.001$ \\
\hline & Sometimes & $301(34.7)$ & $567(65.3)$ & $1.5(1.1-2.1)$ & 0.01 \\
\hline & Never & $72(45)$ & $88(55)$ & (reference) & (reference) \\
\hline \multirow[t]{3}{*}{ Lack of sleeping } & Always & $25(18.7)$ & $109(81.3)$ & $3.8(2.3-6.2)$ & $<0.001$ \\
\hline & Sometimes & $219(32.7)$ & $451(67.3)$ & $1.8(1.3-2.4)$ & $<0.001$ \\
\hline & Never & $147(47)$ & $166(53)$ & (reference) & (reference) \\
\hline \multirow[t]{3}{*}{ Habitual physical exercise } & None & $212(32.8)$ & $434(67.2)$ & $1.6(1.1-2.4)$ & 0.01 \\
\hline & Max $2 \mathrm{~h} /$ week & $126(35.9)$ & $225(64.1)$ & $1.4(0.9-2.1)$ & 0.09 \\
\hline & $>2 \mathrm{~h} /$ week & $53(44.5)$ & $66(55.5)$ & (reference) & (reference) \\
\hline \multirow[t]{3}{*}{ Vegetables and fruits } & Frequent consumption & $225(36.1)$ & $398(63.9)$ & $0.8(0.4-1.4)$ & 0.5 \\
\hline & Moderate consumption & $147(33.9)$ & $286(66.1)$ & $0.9(0.5-1.6)$ & 0.7 \\
\hline & Rare/no consumption & $21(32.3)$ & $44(67.7)$ & (reference) & (reference) \\
\hline \multirow[t]{3}{*}{ Fried food frequency } & Frequent consumption & $89(31.7)$ & $192(68.3)$ & $1.3(0.7-2.3)$ & 0.2 \\
\hline & Moderate consumption & $276(35.8)$ & $494(64.2)$ & $1.1(0.6-1.8)$ & 0.6 \\
\hline & Rare/no consumption & $26(38.8)$ & $41(61.2)$ & (reference) & (reference) \\
\hline \multirow[t]{3}{*}{ Meat consumption frequency } & Frequent consumption & $86(36.6)$ & $149(63.4)$ & $0.9(0.5-1.4)$ & 0.7 \\
\hline & Moderate consumption & $265(34.3)$ & $507(65.7)$ & $1.01(0.6-1.5)$ & 0.9 \\
\hline & Rare/no consumption & $38(34.5)$ & $72(65.5)$ & (reference) & (reference) \\
\hline \multirow[t]{3}{*}{ With bread } & Frequent consumption & $225(32.8)$ & $460(67.2)$ & $1.6(1.07-2.3)$ & 0.02 \\
\hline & Moderate consumption & $110(35.8)$ & $197(64.2)$ & $1.4(0.9-2.1)$ & 0.1 \\
\hline & Rare/no consumption & $51(44)$ & $65(56)$ & (reference) & (reference) \\
\hline
\end{tabular}

Table 3. Significant factors associated with GERD (Multivariate analysis)

\begin{tabular}{|c|c|c|c|c|}
\hline \multicolumn{2}{|l|}{ Factor } & \multicolumn{3}{|c|}{ Multivariate } \\
\hline & & OR & $95 \% \mathrm{CI}$ & P-value \\
\hline \multirow[t]{3}{*}{ Education level } & $<$ High school & 0.5 & $0.3-0.8$ & 0.004 \\
\hline & High school graduation & 1.1 & $0.7-1.5$ & 0.6 \\
\hline & University & \multicolumn{3}{|c|}{ Reference } \\
\hline \multirow[t]{2}{*}{ Use of PPIs } & Yes & 2.2 & $1-5$ & 0.045 \\
\hline & No & \multicolumn{3}{|c|}{ Reference } \\
\hline \multirow[t]{2}{*}{ Use of $\mathrm{H}_{2}$ Ras } & Yes & 4.7 & $2.3-9.4$ & $<0.001$ \\
\hline & No & \multicolumn{3}{|c|}{ Reference } \\
\hline \multirow[t]{2}{*}{ Use of NSAIDs } & Yes & 1.6 & $1.2-2.3$ & 0.002 \\
\hline & No & \multicolumn{3}{|c|}{ Reference } \\
\hline \multirow[t]{2}{*}{ Habit of quick eating } & Yes & 1.5 & $1.1-2$ & 0.008 \\
\hline & No & \multicolumn{3}{|c|}{ Reference } \\
\hline \multirow[t]{3}{*}{ Extra salt on regular meals } & Always & 1.2 & $0.7-2$ & 0.4 \\
\hline & Sometimes & 1.5 & $1.05-2$ & 0.02 \\
\hline & Never & \multicolumn{3}{|c|}{ Reference } \\
\hline \multirow[t]{3}{*}{ Lack of sleeping } & Always & 2.6 & $1.5-4.8$ & 0.001 \\
\hline & Sometimes & 1.6 & $1.2-2.3$ & 0.003 \\
\hline & Never & \multicolumn{3}{|c|}{ Reference } \\
\hline \multirow[t]{3}{*}{ With bread } & Frequent consumption & 1.7 & $1.05-2.7$ & 0.02 \\
\hline & Moderate consumption & 1.5 & $0.9-2.6$ & 0.09 \\
\hline & Rare/no consumption & \multicolumn{3}{|c|}{ Reference } \\
\hline
\end{tabular}

\section{Discussion}

Our findings show that prevalence of GERD was about $28 \%$. The most important risk factors were taking H2RAs medicine, insufficient sleep, taking PPIs medicine, consumption of white bread, eating meals very fast, taking in extra salt with food, and education level respectively. Based on our search at the time, a few studies studied the relationship between prevalence of GERD and its risk factors in Iran (5-7). In this study, the prevalence of GERD 
was estimated as $28 \%$, while previous studies reported 18.2 and $12.3 \%$ in Tehran and Gonbad-Kavous respectively $(6,13)$. The prevalence of GERD in Iran has been reported as much higher than the other Asian countries. However, Iran GERD prevalence can be comparable with those in the USA, Turkey, southern India, Greece and Moscow $(1,4$, $14,15)$. The less prevalence of GERD in Asian countries was attributed to consuming less oily foods $(1,9)$. The least GERD prevalence was reported for China and the most for the USA (1). This high prevalence may be explained by the fact that the population of Iran has experienced major dietary changes such as more consumption of fast food in the past decades, in line with changes in socioeconomic factors. We did not find significant relation between age and GERD like three other studies $(9,16,17)$; two studies reported a positive relation, $(18,19)$ and two, reverse relation $(20,21)$. Age mean of our samples was low, because of that, we did not find significant association between age and GERD. Univariate analysis showed that obesity is a predictor of GERD, however, adjusted results did not. Yamamichi reported adjusted BMI as a predictor of GERD (2). Other studies also showed BMI as a predictor of GERD $(6,9,22-24)$. HUNT2, a population based study, provided some evidence that obesity had a positive relationship with GERD (25). Furthermore, a systematic review (26) also showed a significant relationship between obesity and GERD. This difference between results may be due to our sample size being lower than previous studies. Taking H2RAs and PPIs in both unadjusted and adjusted analysis appeared to be significant predictors of GERD. This result was concordant with results of Yamamichi et.al. (2). This study evaluated the relationship between GERD and a wide range of life-style risk factors. Among them, habit of midnight snack, quick eating, having dinner very late, not having breakfast, drinking tea, taking extra salt when having dinners, carbonated drinks, insufficient sleep, and consumption of white bread appeared to be statistically significant predictors of GERD. All the above-mentioned adjusted risk factors in the Japanese study (2) were also confirmed as statistically significant predictors of GERD and concordant with our results. The most significant adjusted variables were insufficient sleep, obesity, having late dinner, and having a snack at night time respectively. We did not find any relationship between drinking coffee and GERD. Nelson et. al. (27), Nocon (23), and Nasseri et. al. did not find any relationship (6), however, Yamamichi et. al. (2) found a moderate significant relationship. In this study, there was no evidence against red meat and GERD, and in turn, fat. Nocon (23), Nasseri (6) and Çela et. al. (9), found similar results. Matsuki (28) in a NERD patient group, and El-Serag et.al. (29) reported lipid as a GERD risk factor. Consumption of extra salt at the time of having meals was reported as a significant predictor of GERD (27), however, Matsuki (28) did not provide any important evidence against it. The association between smoking and GERD was confirmed in our findings and by $(6,9,23,30)$. Different studies showed different results in different directions on the relationship between regular exercise (physical activity) and GERD $(5,27,31-33)$. This study provided a pattern against lack of exercise, the higher amount of exercise, the lower risk of GERD. However, our study does have some limitations. Firstly, we could not use clinical diagnosis for GERD. The second limitation of this study is that analysis requires reliable sources of data gained from prospective cohort studies, while we carried out a cross sectional design. Third, the quality and precision of the estimations and associations primarily depend on the quality of the recorded data.

\section{Conclusions}

This cross-sectional study showed a high prevalence of GERD in Iran and provided evidence on the association between GERD and taking H2RAs medicine, insufficient sleep, taking PPIs medicine, consumption of white bread, eating meals very fast, and taking in extra salt with food. This study has some strong advantages including the sample size and setting of study, which can be considered as a representative of the whole of Iran as a matter of high immigration in and in turn, the results could be generalised to the country. However, this is a cross-sectional study and prone to the usual pitfalls of such studies.

\section{Acknowledgments:}

The authors appreciate the staff of Qom University of Medical Sciences who kindly participated in our study. This project was financially supported by Qom University of Medical Sciences. Proposal code was MUQ.REC.1393.135.

\section{Conflict of Interest:}

There is no conflict of interest to be declared.

\section{Authors' contributions:}

All authors contributed to this project and article equally. All authors read and approved the final manuscript. 


\section{References:}

1) Ronkainen J, Agréus L. Epidemiology of reflux symptoms and GORD. Best Pract Res Clin Gastroenterol. 2013; 27(3): 325-37. doi: 10.1016/j.bpg.2013.06.008. PMID: 23998972.

2) Yamamichi N, Mochizuki S, Asada-Hirayama I, Mikami-Matsuda R, Shimamoto T, Konno-Shimizu M, et al. Lifestyle factors affecting gastroesophageal reflux disease symptoms: a cross-sectional study of healthy 19864 adults using FSSG scores. BMC medicine. 2012; 10(1): 1. doi: 10.1186/1741-7015-10-45. PMID: 22554226, PMCID: PMC3353848.

3) Song JH, Chung SJ, Lee JH, Kim YH, Chang DK, Son HJ, et al. Relationship between gastroesophageal reflux symptoms and dietary factors in Korea. J Neurogastroenterol Motil. 2011; 17(1): 54-60. doi: 10.5056/jnm.2011.17.1.54. PMID: 21369492, PMCID: PMC3042219.

4) Wang HY, Leena KB, Plymoth A, Hergens MP, Yin L, Shenoy KT, et al. Prevalence of gastro-esophageal reflux disease and its risk factors in a community-based population in southern India. BMC Gastroenterol. 2016; 16(1): 36. doi: 10.1186/s12876-016-0452-1. PMID: 26979399, PMCID: PMC4791779.

5) Khoshbaten M. Gastro-esophageal reflux disease in northwestern Tabriz, Iran. Indian J Gastroenterol. 2002; 22(4): 138-9. PMID: 12962436.

6) Nasseri-Moghaddam S, Mofid A, Ghotbi MH, Razjouyan H, Nouraie M, Ramard AR, et al. Epidemiological study of gastro - oesophageal reflux disease: reflux in spouse as a risk factor. Aliment Pharmacol Ther. 2008; 28(1): 144-53. doi: 10.1111/j.1365-2036.2008.03708.x. PMID: 18410559.

7) Esmaillzadeh A, Keshteli AH, Feizi A, Zaribaf F, Feinle-Bisset C, Adibi P. Patterns of diet - related practices and prevalence of gastro - esophageal reflux disease. Neurogastroenterol Motil. 2013; 25(10): 831-e638. doi: 10.1111/nmo.12192. PMID: 23895231.

8) Minatsuki C, Yamamichi N, Shimamoto T, Kakimoto H, Takahashi Y, Fujishiro M, et al. Background factors of reflux esophagitis and non-erosive reflux disease: a cross-sectional study of 10,837 subjects in Japan. PLoS One. 2013; 8(7): e69891. doi: 10.1371/journal.pone.0069891. PMID: 23922844, PMCID: PMC3724738.

9) Çela L, Kraja B, Hoti K, Toçi E, Muja H, Roshi E, et al. Lifestyle characteristics and gastroesophageal reflux disease: a population-based study in Albania. Gastroenterology research and practice. $2013 ; 2013$. doi: 10.1155/2013/936792.

10) Danjo A, Yamaguchi K, Fujimoto K, Saitoh T, Inamori M, Ando T, et al. Comparison of endoscopic findings with symptom assessment systems (FSSG and QUEST) for gastroesophageal reflux disease in Japanese centres. J Gastroenterol Hepatol. 2009; 24(4): 633-8. doi: 10.1111/j.1440-1746.2008.05747.x. PMID: 19220681.

11) Nonaka T, Kessoku T, Ogawa Y, Yanagisawa S, Shiba T, Sakaguchi T, et al. Comparative study of 2 different questionnaires in Japanese patients: the quality of life and utility evaluation survey technology questionnaire (QUEST) versus the frequency scale for the symptoms of gastroesophageal reflux disease questionnaire (FSSG). J Neurogastroenterol Motil. 2013; 19(1): 54-60. doi: 10.5056/jnm.2013.19.1.54. PMID: 23350048, PMCID: PMC3548128.

12) Kusano M, Shimoyama Y, Sugimoto S, Kawamura O, Maeda M, Minashi K, et al. Development and evaluation of FSSG: frequency scale for the symptoms of GERD. J Gastroenterol. 2004; 39(9): 888-91. doi: 10.1007/s00535-004-1417-7. PMID: 15565409.

13) Aletaha N, Akram P, Norae S, Shahakbar F, Falakzade R. In the city of Gonbad-e Qabus gastroesophageal reflux disease: prevalence and risk factors. Journal of Medical Council of Islamic Republic of Iran. 2009; 28(2).

14) Spantideas N, Drosou E, Bougea A, Assimakopoulos D. Gastroesophageal reflux disease symptoms in the Greek general population: prevalence and risk factors. Clin Exp Gastroenterol. 2016; 9: 143-9. doi: 10.2147/CEG.S103485. PMID: 27382324, PMCID: PMC4922744.

15) Bor S, Lazebnik LB, Kitapcioglu G, Manannikof I, Vasiliev Y. Prevalence of gastroesophageal reflux disease in Moscow. Dis Esophagus. 2016; 29(2): 159-65. doi: 10.1111/dote.12310. PMID: 25604401.

16) Haque M, Wyeth JW, Stace NH, Talley NJ, Green R. Prevalence, severity and associated features of gastro-oesophageal reflux and dyspepsia: a population-based study. N Z Med J. 2000; 113(1110): 178-81. PMID: 10917077.

17) Kennedy T, Jones R. The prevalence of gastro - oesophageal reflux symptoms in a UK population and the consultation behaviour of patients with these symptoms. Aliment Pharmacol Ther. 2000; 14(12): 1589-94. doi: 10.1046/j.1365-2036.2000.00884.x. PMID: 11121906. 
18) Bolin TD, Korman MG, Hansky J, Stanton R. Heartburn: community perceptions. J Gastroenterol Hepatol. 2000; 15(1): 35-9. doi: 10.1046/j.1440-1746.2000.02051.x. PMID: 10719745.

19) Stanghellini V. Three-month prevalence rates of gastrointestinal symptoms and the influence of demographic factors: results from the Domestic/International Gastroenterology Surveillance Study (DIGEST). Scand J Gastroenterol Suppl. 1999; 231: 20-8. doi: 10.1080/003655299750025237. PMID: 10565620.

20) Farup C, Kleinman L, Sloan S, Ganoczy D, Chee E, Lee C, et al. The impact of nocturnal symptoms associated with gastroesophageal reflux disease on health-related quality of life. Arch Intern Med. 2001; 161(1): 45-52. doi: 10.1001/archinte.161.1.45. PMID: 11146697.

21) Locke GR 3rd, Talley NJ, Fett SL, Zinsmeister AR, Melton LJ 3rd. Prevalence and clinical spectrum of gastroesophageal reflux: a population-based study in Olmsted County, Minnesota. Gastroenterology. 1997; 112(5): 1448-56. doi: 10.1016/S0016-5085(97)70025-8. PMID: 9136821.

22) Kraja B, Burazeri G, Prifti S. Anthropometric indices and gastro-esophageal reflux disease in adult population in Tirana, Albania. Med Arh. 2008; 62(3): 139-41. PMID: 18822939.

23) Nocon M, Labenz J, Willich SN. Lifestyle factors and symptoms of gastro - oesophageal reflux - a population - based study. Aliment Pharmacol Ther. 2006; 23(1): 169-74. doi: 10.1111/j.13652036.2006.02727.x. PMID: 16393294.

24) Festi D, Scaioli E, Baldi F, Vestito A, Pasqui F, Di Biase AR, et al. Body weight, lifestyle, dietary habits and gastroesophageal reflux disease. World J Gastroenterol. 2009; 15(14): 1690-701. doi: 10.3748/wjg.15.1690. PMID: 19360912, PMCID: PMC2668774.

25) Fujimoto K. Review article: prevalence and epidemiology of gastro - oesophageal reflux disease in Japan. Aliment Pharmacol Ther. 2004; 20 Suppl 8: 5-8. doi: 10.1111/j.1365-2036.2004.02220.x. PMID: 15575864.

26) Hampel H, Abraham NS, El-Serag HB. Meta-analysis: obesity and the risk for gastroesophageal reflux disease and its complications. Ann Intern Med. 2005; 143(3): 199-211. doi: 10.7326/0003-4819-143-3200508020-00006. PMID: 16061918.

27) Nilsson M, Johnsen R, Ye W, Hveem K, Lagergren J. Lifestyle related risk factors in the aetiology of gastro-oesophageal reflux. Gut. 2004; 53(12): 1730-5. doi: 10.1136/gut.2004.043265. PMID: 15542505, PMCID: PMC1774312.

28) Matsuki N, Fujita T, Watanabe N, Sugahara A, Watanabe A, Ishida T, et al. Lifestyle factors associated with gastroesophageal reflux disease in the Japanese population. J Gastroenterol. 2013; 48(3): 340-9. doi: 10.1007/s00535-012-0649-1. PMID: 22911169.

29) El-Serag HB, Satia JA, Rabeneck L. Dietary intake and the risk of gastro-oesophageal reflux disease: a cross sectional study in volunteers. Gut. 2005; 54(1): 11-7. doi: 10.1136/gut.2004.040337. PMID: 15591498, PMCID: PMC1774352.

30) Robertson LA, Evans CJ, Lee AJ, Allan PL, Ruckley CV, Fowkes FG. Incidence and risk factors for venous reflux in the general population: Edinburgh Vein Study. Eur J Vasc Endovasc Surg. 2014; 48(2): 208-14. doi: 10.1016/j.ejvs.2014.05.017. PMID: 24951373.

31) Djärv T, Wikman A, Nordenstedt H, Johar A, Lagergren J, Lagergren P. Physical activity, obesity and gastroesophageal reflux disease in the general population. World J Gastroenterol. 2012; 18(28): 3710-4. doi: 10.3748/wjg.v18.i28.3710. PMID: 22851863, PMCID: PMC3406423.

32) Mohammed I, Nightingale P, Trudgill NJ. Risk factors for gastro - oesophageal reflux disease symptoms: a community study. Aliment Pharmacol Ther. 2005; 21(7): 821-7. doi: 10.1111/j.1365-2036.2005.02426.x. PMID: 15801917.

33) Nandurkar S, Locke GR 3rd, Fett S, Zinsmeister AR, Cameron AJ, Talley NJ. Relationship between body mass index, diet, exercise and gastro - oesophageal reflux symptoms in a community. Aliment Pharmacol Ther. 2004; 20(5): 497-505. doi: 10.1111/j.1365-2036.2004.02156.x. PMID: 15339321. 